\title{
LOCAL ACTION OF PROGESTERONE LEADING TO POLYSPERMIC FERTILIZATION IN PIGS
}

\author{
R. H. F. HUNTER* \\ A.R.C. Unit of Reproductive Physiology and Biochemistry, \\ University of Cambridge
}

(Received 20th December 1971, accepted 4th February 1972)

\begin{abstract}
Summary. Microdroplets of progesterone were injected unilaterally beneath the serosa of the tubal isthmus and uterotubal junction in thirty pigs, a total of $1 \mathrm{mg}$ in $0.1 \mathrm{ml}$ of oil being deposited 8 to $12 \mathrm{hr}$ before ovulation. A similar volume of the vehicle was injected as a control into the contralateral tubal structures. All animals were inseminated intracervically approximately $2 \mathrm{hr}$ before these surgical procedures and slaughtered between $6 \mathrm{hr} 20 \mathrm{~min}$ and $14 \mathrm{hr} 30 \mathrm{~min}$ after completion of ovulation.

Polyspermic fertilization was found in $32.3 \%$ of the eggs recovered from the progesterone-treated tubes compared with $9.7 \%$ of those from the control tubes $(P<0.01)$. The number of tubes yielding polyspermic eggs was also significantly higher on the progesterone-treated side $(P<0.01)$. Injection of progesterone $8 \mathrm{hr}$ before ovulation resulted in $38.2 \%$ polyspermic eggs from the treated tubes, dispermy being the principal anomaly of fertilization. In both dispermic and trispermic eggs, the female and a single male pronucleus were uniting, the accessory male element(s) remaining in the opposite hemisphere of the egg.

It is concluded that relaxation of the oedematous tissues of the isthmus and uterotubal junction occurs after local injection of progesterone. In these circumstances, polyspermy is thought to originate principally from increased numbers of spermatozoa reaching the site of fertilization, although a direct effect of progesterone on the membranes of the gametes cannot be excluded. The disposition of the accessory male pronuclei in the polyspermic eggs raises the question whether polyploids usually arise from polyspermy or whether delayed cleavage and cytoplasmic fragmentation are more frequent sequelae to this condition in pigs.
\end{abstract}

\section{INTRODUGTION}

Among the various anomalies of mammalian fertilization observed at the level of the light microscope, that involving penetration of the ooplasm by more than one spermatozoon has been documented for many species including the rat, mouse, hamster, guinea-pig, rabbit and pig (for review, see Austin \& Bishop,

* Present address: School of Agriculture, University of Edinburgh, West Mains Road, Edinburgh 9.

G 
1957; Austin \& Walton, 1960; Austin, 1961; Pikó, 1961). In the domestic pig, polyspermy has been recorded under a wide range of experimental conditions, although it is best known as a sequel to delayed mating or insemination (Pitkjanen, 1955; Hancock, 1959; Thibault, 1959; Hunter, 1967a) when 10 to $15 \%$ of the eggs may be penetrated by two or more spermatozoa. This anomaly reaches a more striking incidence in pigs ( 40 to $60 \%$ ) when injections of progesterone are given shortly before ovulation (Day \& Polge, 1968) or when ovulation is induced during the luteal phase of the oestrous cycle (Hunter, 1967b). On the basis of these findings in situations of enhanced progesterone levels, a simple hypothesis to explain in part the occurrence of polyspermy in pigs has been proposed by Hunter \& Léglise (1971). They suggest that progesterone, whether from endogenous or exogenous sources, may be involved in inducing relaxation of the musculature of the tubal isthmus and uterotubal junction, allowing passage of more spermatozoa to the site of fertilization, thus increasing the risk of polyspermic fertilization. Considerable support for this hypothesis was obtained from experiments in which the isthmus of the Fallopian tube was resected on one side of the tract, the remaining portions of the tube undergoing end-to-end anastomosis (Hunter \& Léglise, 1971). In these circumstances, 32\% of the fertilized eggs recovered from the anastomosed tube of mated animals were polyspermic compared with less than $1 \%$ of the eggs recovered from the control tube.

In view of the above evidence which suggests an interaction between progesterone and the isthmus in regulating sperm transport in the pig, a technique has been developed for depositing progesterone locally in the tubular structures. The present study is concerned with the nature and extent of the polyspermy that ensues when tubal function is modified by this approach.

\section{MATERIALS AND METHODS}

\section{Animals}

Thirty-four Large White $\times$ Essex gilts weighing 120 to $140 \mathrm{~kg}$, and aged between 6 and 9 months, were used. They were examined twice daily in the presence of a mature boar, and those showing symptoms of pro-oestrus were individually identified.

\section{Induction of ovulation}

The time of ovulation was controlled by a single intramuscular injection of 500 i.u. HCG (Lutormone, Burroughs Wellcome) given during late prooestrus. This stage was determined by the swelling and colour of the vulva together with observations on the behaviour of the animals. Ovulation was assumed to occur in these Large White $\times$ Essex gilts some 41 to $42 \mathrm{hr}$ after injection of HCG (Hunter, 1967c).

\section{Collection and insemination}

Semen was collected from a single Large White boar of proven fertility. Using a spiral rubber catheter (Melrose \& O'Hagan, 1961), approximately $120 \mathrm{ml}$ of undiluted semen were instilled intracervically within $15 \mathrm{~min}$ of collection. Only 
animals exhibiting oestrus were inseminated, this being performed about $2 \mathrm{hr}$ before surgery and 10 to $14 \mathrm{hr}$ before ovulation.

\section{Progesterone solution}

Crystalline progesterone (British Drug Houses Ltd) was dissolved in pure corn oil to make a solution containing $10 \mathrm{mg} / \mathrm{ml}$, and stored in darkness at room temperature $\left(18^{\circ} \mathrm{C}\right)$. A fresh solution was prepared during the course of the experiment, and the concentration of progesterone in the original solution was chemically verified.

\section{Experimental design}

Microdroplets of the progesterone solution were injected 8,10 or $12 \mathrm{hr}$ before ovulation, ten animals being used at each interval. Both Fallopian tubes were subjected to identical surgical procedures (see below) in each experiment, one side of the tract receiving the progesterone solution whilst the other was given a control injection of a similar volume of oil to which hormones had not been added. As an additional control experiment, four animals were similarly injected with the oil vehicle on one side of the tract, whereas insertion of the dry needle only was performed on the contralateral side. This experiment was considered necessary in order to distinguish between the effect of the 'control' oil and that of a systemic effect of progesterone treatment.

\section{Surgical procedures}

Anaesthesia was induced by intravenous injection of pentobarbitone sodium followed by closed-circuit administration of Fluothane and oxygen. The reproductive tract was exposed by a mid-ventral abdominal incision, and the ovaries examined to confirm that ovulation had not yet occurred. The side of the tract receiving the progesterone injections was usually that with the larger number of preovulatory follicles. Microdroplets of the control oil and progesterone solution were injected using 26-gauge intradermal needles ( $\frac{3}{8}$ in. long) attached to $1-\mathrm{ml}$ plastic syringes (Gillette Scimitar) which were discarded after use. Microdroplets of oil $(0.01 \mathrm{ml})$ were deposited under the serosa of the tract in the region of the uterotubal junction and lower portion of the isthmus (Text-fig. 1) in a series of eight to ten injections, but the precise site of these depended on the architecture of the blood vessels conspicuous in this area. Care was taken to avoid entering such vessels. A total volume of $0.1 \mathrm{ml}$ was injected on each side of the tract and, although bleeding was rarely seen on withdrawal of the needle, slight seepage of the oily solution occasionally took place. The side of the tract receiving the progesterone solution was marked in the uterine wall with Indian ink. After completion of these procedures, the reproductive tract was returned to the peritoneal cavity, and the abdominal wall sutured in three layers. Aseptic precautions were observed throughout the above stages. The animals remained in a warm $\left(18^{\circ} \mathrm{C}\right)$ recovery pen overnight, and were slaughtered at a local abattoir the following day between $6 \mathrm{hr} 20 \mathrm{~min}$ and $14 \mathrm{hr} 30 \mathrm{~min}$ after completion of ovulation.

\section{Post-mortem examination}

Animals were stunned electrically, and the reproductive tract was removed 
3 to $4 \mathrm{~min}$ later before scalding or evisceration. The tract was transported to the laboratory in a warm vacuum flask, the Fallopian tubes were dissected free of their ligaments, and the eggs flushed with physiological saline into polythene Petri dishes. Eggs were prepared as whole mounts (Chang, 1952) and fixed for at least $24 \mathrm{hr}$ in $25 \%$ acetic alcohol. The preparations were then rinsed in absolute alcohol, stained with $0.5 \%$ natural orcein in $45 \%$ acetic acid, and examined in detail by phase-contrast microscopy. The number and disposition of pronuclei and/or sperm heads in the cytoplasm were recorded, as were details of the polar bodies. In instances where more than two pronuclei were observed, a search was made for remnants of the sperm mid-piece or tail in association with these structures. The latter procedure was greatly facilitated by

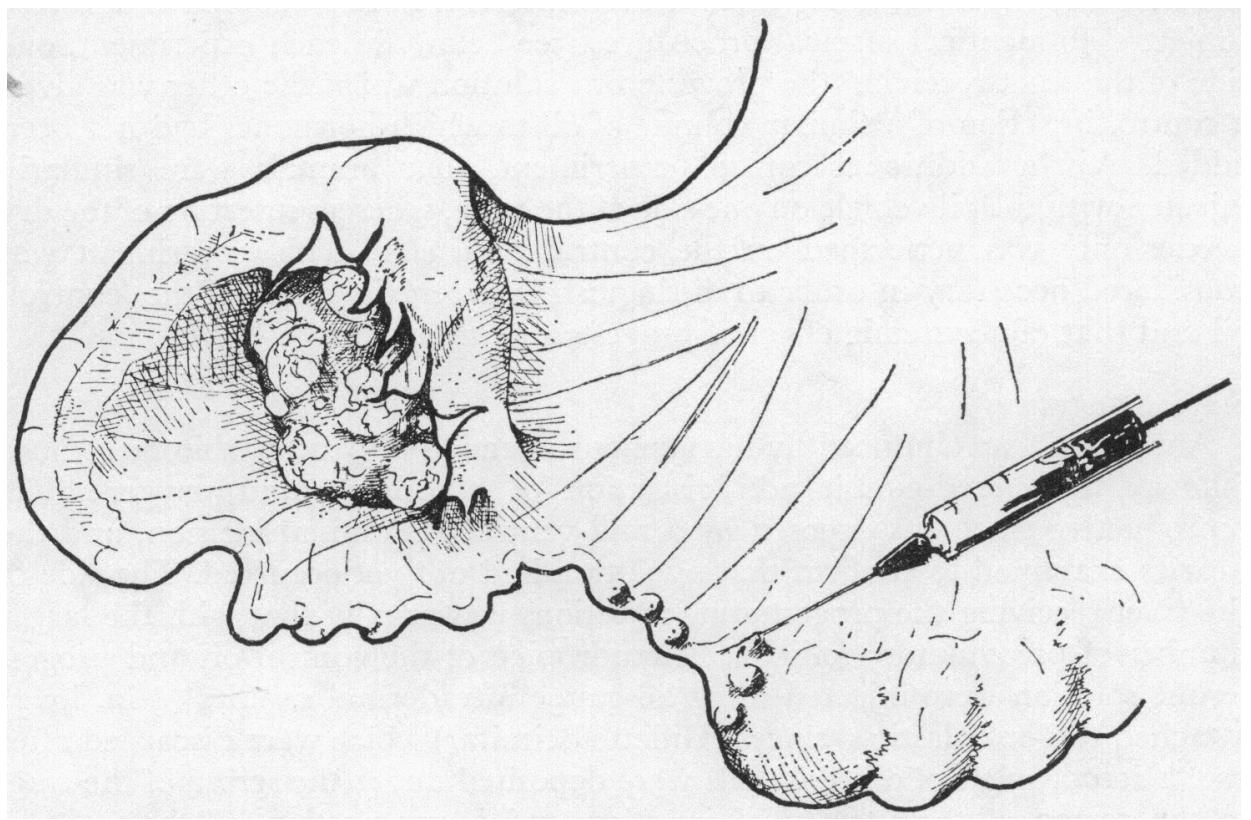

TEXT-FIG. 1. Semi-diagrammatic illustration of the upper reproductive tract to show the region of the uterotubal junction and isthmus injected with either a solution of progesterone or the control oil vehicle. The total volume injected beneath the serosa on each side of the tract was $0.1 \mathrm{ml}$, but the swellings at the sites of injection are much exaggerated. Preovulatory Graafian follicles are partially enveloped by the infundibulum.

a re-examination of the eggs some 24 to $48 \mathrm{hr}$ after the initial staining, most of the orcein being cleared from the ooplasm at this stage with $45 \%$ acetic acid. Photomicrographs were taken of suitable preparations.

\section{RESULTS}

\section{Ovarian details}

Recent ovulations were observed on both ovaries of all animals at autopsy, there being no evidence to indicate any failure in response to the pro-oestrous injection of HGG. However, a total of fifteen Graafian follicles of mean dia- 
meter larger than $5 \mathrm{~mm}$ (usually 7 to $9 \mathrm{~mm}$ ) was observed in nine animals at autopsy.

In the thirty gilts treated unilaterally with progesterone, a total of 375 recent ovulations was counted at autopsy, giving a mean of 12.5 ovulations per animal, with a range from eight to seventeen. The four control animals not receiving progesterone injections had a total of fifty-nine recent ovulations (mean 14.8), with a range from eight to twenty-five, one of these animals representing an instance of superovulation.

\section{Egg recovery}

All thirty animals treated with progesterone yielded eggs from both Fallopian tubes; none was found in the uterus. A total of 344 eggs was obtained, corresponding to an overall recovery of $91.8 \%$. The proportion of eggs recovered within individual animals ranged from $72.7 \%$ to $100 \%$, but there was little difference in the mean percentage recoveries between the control and progesteronetreated tubes in any of the groups (Table 1). Complete denudation of the

TABLE 1

NUMBER AND PROPORTION OF EGGS RECOVERED FROM THE FALLOPIAN TUBES OF THIRTY PIGS

\begin{tabular}{c|c|cc|c|cc}
\hline \multirow{2}{*}{$\begin{array}{c}\text { Interval from HCG } \\
\text { to tubal injection } \\
(\text { hr })^{*}\end{array}$} & \multicolumn{3}{|c|}{ Control tube } & \multicolumn{3}{|c}{ Progesterone-treated tube } \\
\cline { 2 - 7 } & $\begin{array}{c}\text { No. of recent } \\
\text { ovulations }\end{array}$ & $\begin{array}{c}\text { No. of eggs } \\
\text { recovered }\end{array}$ & $\%$ & $\begin{array}{c}\text { No. of recent } \\
\text { ovulations }\end{array}$ & $\begin{array}{c}\text { No. of eggs } \\
\text { recovered }\end{array}$ & $\%$ \\
\hline 30 & 53 & 49 & $92 \cdot 5$ & 77 & 66 & $85 \cdot 7$ \\
32 & 55 & 51 & $92 \cdot 7$ & 60 & 56 & $93 \cdot 3$ \\
34 & 51 & 46 & $90 \cdot 2$ & 79 & 76 & $96 \cdot 2$ \\
\hline Total & 159 & 146 & $91 \cdot 8$ & 216 & 198 & $91 \cdot 7$ \\
\hline
\end{tabular}

Control oil or a solution of progesterone was injected beneath the serosa of the uterotubal junction and lower isthmus at various intervals after an ovulation-inducing injection of HCG.

* Ten animals were treated at each time interval.

recovered eggs from the cells of the cumulus oophorus and corona radiata had occurred in all except two of the gilts. In the four animals not receiving injections of progesterone, a total of fifty-two eggs was recovered $(88 \cdot 1 \%)$, all of which were denuded.

\section{Fertilization and cytological details}

Fertilized eggs were recovered from both Fallopian tubes of all the treated animals, the number of fertilized eggs examined at each of these time intervals being shown in Table 2. All but one of the 344 recovered eggs were fertilized; the other egg was presumed to be atretic, being completely denuded and having a peripherally placed dictyate nucleus. Fifty-one of the fifty-two eggs recovered from the four animals not injected with progesterone were fertilized, the remaining egg exhibiting a first polar body and compact arrangement of chromosomes on the second metaphase spindle. Spermatozoa were not detected on or in the zona pellucida of this egg. 
Polyspermic fertilization was found in sixty-four of the 198 eggs $(32.3 \%)$ recovered from the progesterone-treated tubes compared with fourteen of the 145 eggs $(9.7 \%)$ from the control tubes $(P<0.01$, see Table 2$)$. The number of tubes yielding polyspermic eggs was also significantly higher on the side receiving injections of progesterone $(80 \%$ versus $36 \%, P<0.01)$. Within the twenty-four animals yielding one or more polyspermic eggs, the proportion of polyspermic eggs recovered from the treated tube was $40.3 \%$ compared with $12.2 \%$ from the control tube. In the four control animals not injected with progesterone, only three of the fifty-one fertilized eggs recovered were polyspermic $(5.9 \%)$, two of the eggs being flushed from a tube subjected to the dry injection procedure.

The incidence and distribution of polyspermy is presented in Table 2.

Treatment with progesterone $34 \mathrm{hr}$ after injection of HCG resulted in the highest levels of polyspermy, $38.2 \%$ and $13.0 \%$ of this condition arising in the treated and control tubes, respectively. The degree of polyspermy is analysed in Table 3. Penetration of the ooplasm by two spermatozoa constituted the principal anomaly of fertilization $(75.7 \%$ of the seventy-eight polyspermic eggs), but a small proportion of trispermic, tetraspermic and pentaspermic eggs was also found. All four abnormal forms of fertilization occurred only when the local injections of progesterone were given $34 \mathrm{hr}$ after injection of HCG (Table 3).

The number of spermatozoa attached to or in the zona pellucida of the recovered eggs was only estimated, since accurate counts could not be made on the whole-mount preparations, especially when sperm numbers were often in the range of 100 to 250 . Nevertheless, the number of spermatozoa on eggs from the progesterone-treated tube was rarely significantly greater than the number on eggs from the control tube, and in four animals it was certainly less. On the other hand, in instances where polyspermic fertilization had occurred, high

\section{EXPLANATION OF PLATE 1}

Phase-contrast photomicrographs of whole-mount preparations of pig eggs recovered from the Fallopian tubes between $6 \mathrm{hr} 20 \mathrm{~min}$ and $14 \mathrm{hr} 30 \mathrm{~min}$ after ovulation. The preparations had been fixed for $24 \mathrm{hr}$ in $25 \%$ acetic alcohol, and stained with $0.5 \%$ orcein in $45 \%$ acetic acid.

Fig. 1. A dispermic egg showing the female and a single male pronucleus uniting in one hemisphere of the egg, and an accessory male pronucleus in the opposite hemisphere. The first and second polar bodies are just out of focus at the lower boundary of the egg. $\times 350$.

FIG. 2. Another dispermic egg with the pronuclei arranged essentially as in Fig. 1. The female pronucleus shows condensation of chromatin on the portion of the nuclear membrane adjoining the male pronucleus. $\times 350$.

Fig. 3. A normally fertilized egg showing the central position assumed by the male and female pronuclei at the commencement of syngamy. Contrast with Figs 1 and $2 . \times 330$. FIG. 4. The three adjoining pronuclei in an egg classified as digynic. No second polar body could be detected on this egg. Only one sperm tail was found in the vitellus. $\times 700$.

FIG. 5. A trispermic egg showing conjugation between the female and a single male pronucleus, the accessory male pronuclei remaining peripherally and independently in the vitellus. $\times 385$.

Fig. 6. Detail of the male and female pronuclei at the commencement of syngamy showing the distinctive pattern of chromatin distribution between the two nuclei. The chromatin is granular in the female and aggregated on the portion of the pronuclear membrane orientated towards the male element. Note the sperm mid-piece in close proximity to the male pronucleus. $\times 700$. 

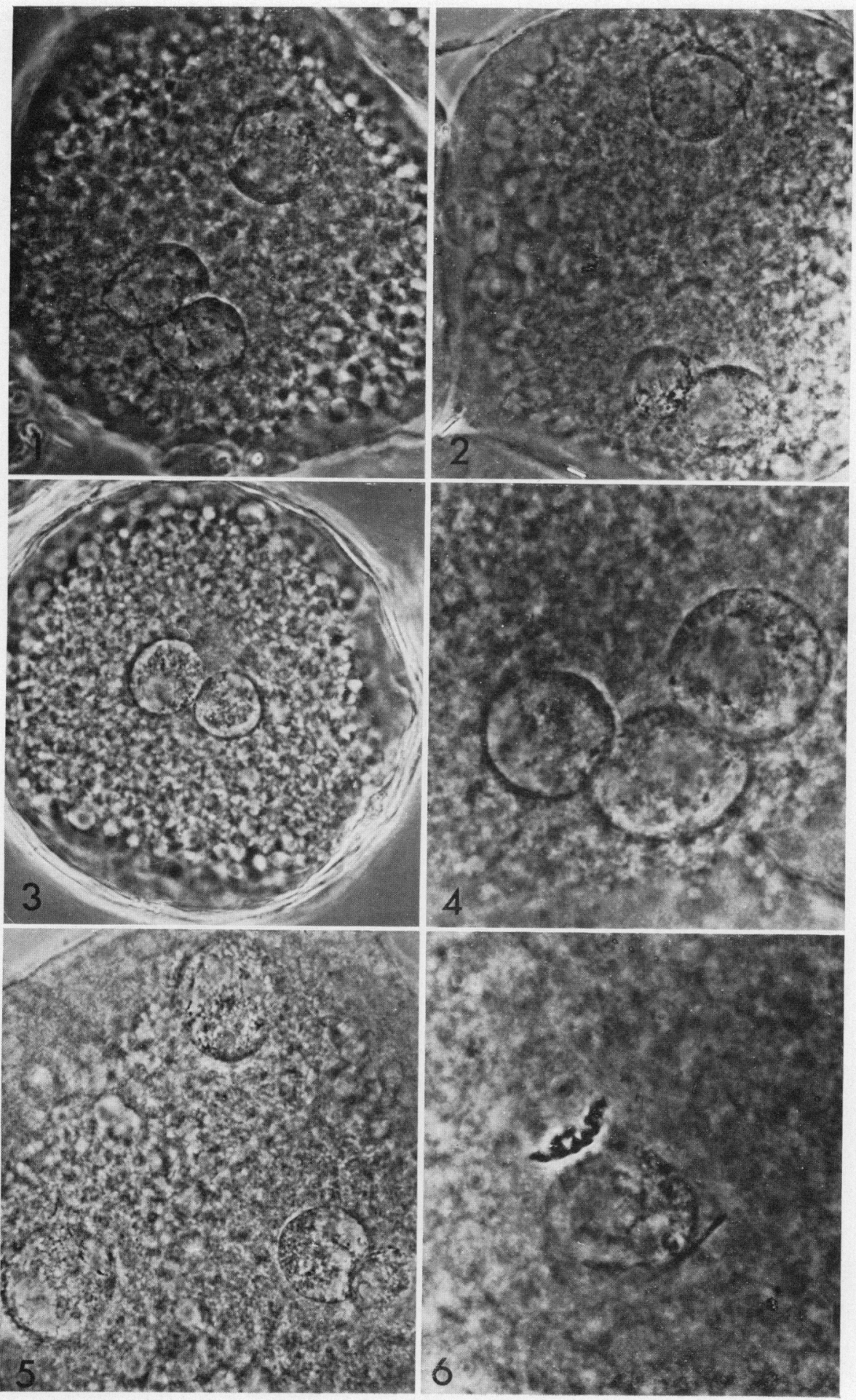

fivinge to. 139 

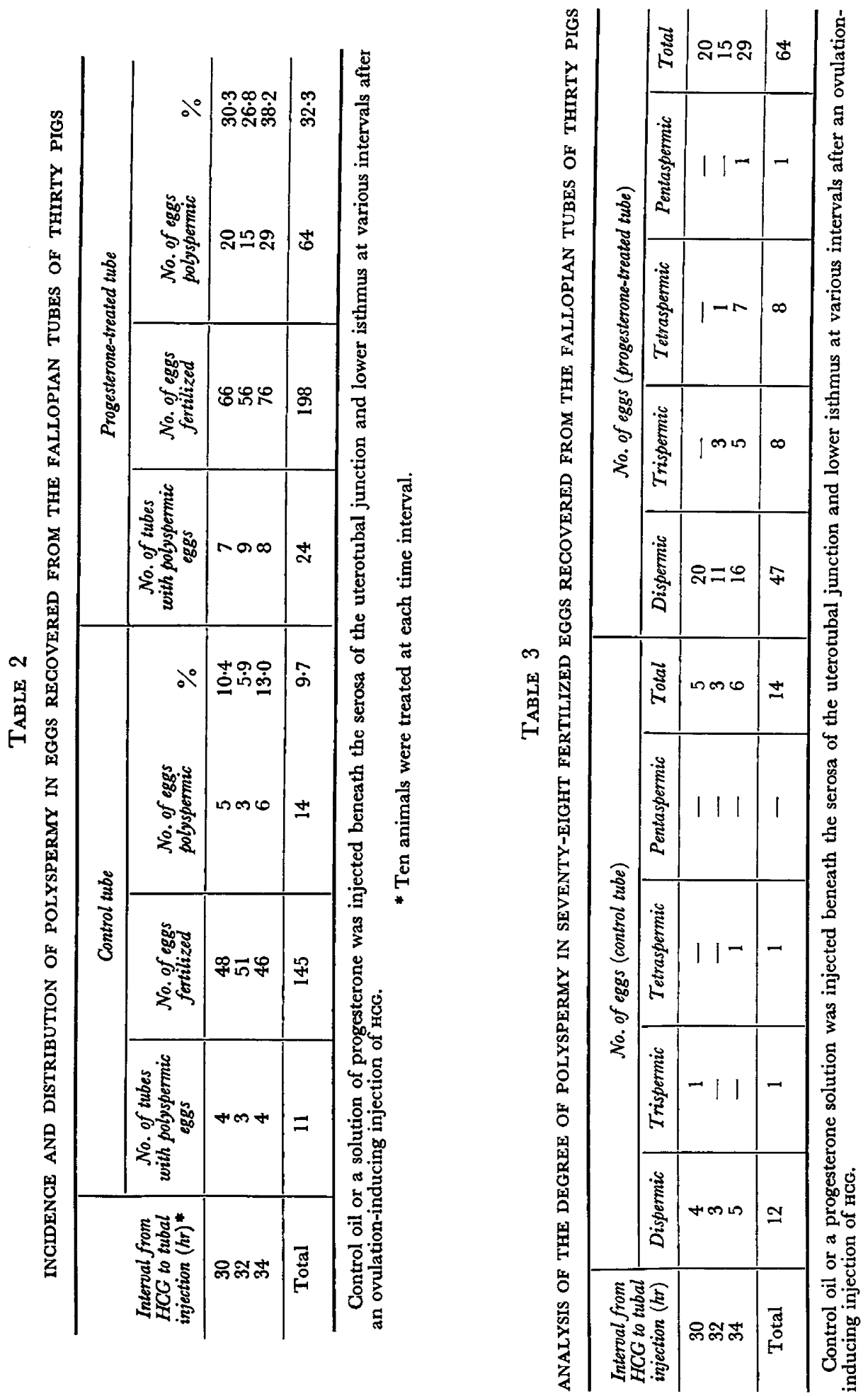
numbers of spermatozoa $(>150)$ were frequently found in the zonae of the polyspermic eggs and usually exceeded the number found on the normally fertilized eggs from the same animal.

The accessory spermatozoa that had penetrated eggs classified as polyspermic were in all instances located in the ooplasm; spermatozoa were not detected in the perivitelline space. In eleven of the total of seventy-eight polyspermic eggs $(14 \cdot 1 \%)$, the accessory spermatozoa were represented by swollen sperm heads situated close to the vitelline membrane and indistinguishable from the fertilizing spermatozoon. All eleven eggs were dispermic and had anaphase or telophase configurations of the second meiotic spindle. In the remaining sixty-seven polyspermic eggs, the accessory male elements had developed into pronuclei at various stages of maturity. These ranged widely in size but, in eggs classified as dispermic, the three pronuclei were of approximately similar volumes.

In the dispermic pronuclear eggs, the disposition of the nuclear elements presented a consistent and characteristic form: the female and a single male pronucleus were uniting in one hemisphere of the egg adjacent to the first and second polar bodies, whilst the accessory male pronucleus was usually located subcentrally or peripherally in the opposite hemisphere of the egg (PI. 1, Figs 1 and 2). This should be contrasted with the centrally placed pronuclei found at the commencement of syngamy in normally fertilized eggs (Pl. 1, Fig. 3). After clearing the whole-mount preparations with $45 \%$ acetic acid, sperm tails generally showing a split at the rostral end of the mid-piece were seen in close association with the male pronuclei in the majority of the dispermic eggs. In one egg considered as digynic, three pronuclei were found in central apposition (Pl. 1, Fig. 4). A second polar body was not located on this egg.

Among the nine trispermic eggs, conjugation of the female and a single male pronucleus was again the rule, the accessory male pronuclei remaining peripherally and usually independently in the ooplasm (PI. 1, Fig. 5). In eggs showing higher forms of polyspermy, the pronuclei were more closely associated and occasionally adjoining but here again, only the female and a single male pronucleus appeared to be undergoing syngamy.

The male and female pronuclei could also often be distinguished by the form and distribution of their chromatin complement, which tended to be granular in the female and aggregated on the portion of the pronuclear membrane orientated towards the male element (Pl. 1, Fig. 6). In the latter, by contrast, the chromatin was arranged in a loose, reticulate fashion. Moreover, the accessory male pronuclei frequently assumed a pear-shaped form, with a slight protuberance directed towards the centre of the egg.

First and second polar bodies were counted on sixty-eight of the seventyeight polyspermic eggs after fixing and staining. Distinction between these structures was usually possible due to the slightly larger size of the first polar body, as well as a more marked difference in the amount and form of its chromatin. In addition, remnants of the meiotic spindle could frequently be detected in association with the second polar body.

A small proportion $(5.8 \%)$ of the 344 eggs examined had progressed to the two-cell stage by the time of autopsy, but none of these eggs was considered 
polyspermic. Cleaved and polyspermic eggs were obtained from the same tube in only one animal. Here, five eggs were recovered, approximately $14 \mathrm{hr}$ after ovulation, of which four were morphologically normal two-cell eggs whereas the fifth was a dispermic, pronuclear egg. The proportion of polyspermic eggs that would have the potential to undergo some degree of mitotic development remains uncertain.

\section{DISCUSSION}

The present experiments have demonstrated that strikingly high levels of polyspermy are found after injecting progesterone beneath the serosa of the isthmus and uterotubal junction of pigs. The manner whereby such injections influence the occurrence of polyspermy has still to be resolved conclusively, but the concept of an alteration in the tubal environment permitting increased numbers of competent spermatozoa to ascend to the site of fertilization is thought to be of prime importance. Cyclic changes in the tissues of the isthmus and the uterotubal junction have been reported by Andersen (1928), these regions being constricted and oedematous during oestrus, so that the passage of excessive numbers of spermatozoa to the ampulla would be impeded. By contrast, relaxation of these tissues takes place during the luteal phase of the oestrous cycle under the influence of endogenous progesterone, and a similar modification is presumed to occur after the local injections of progesterone (see Hunter \& Léglise, 1971). In this situation, a proportion of the large numbers of spermatozoa that normally accumulate in the region of the uterotubal junction in pigs after mating (du Mesnil du Buisson \& Dauzier, 1955; Rigby, 1966) may pass directly into the isthmus, and so to the ampulla with very little quantitative regulation. Although the number of spermatozoa observed about eggs recovered from the two sides of the tract was not always greater on the side treated with progesterone, this is probably because the situation that obtained at the moment of sperm penetration had been obscured by the subsequent attachment of spermatozoa. Nevertheless, the number of spermatozoa on and in the zonae of polyspermic eggs was usually high $(>150)$, and tended to exceed significantly the number on normally fertilized eggs from the same animal.

Although the principal rôle of progesterone in inducing polyspermy in the present experiments is thought to be due to an alteration in the physiological state of the tubal structures, it is realized that the injected progesterone may also have acted directly on the membranes of the gametes to modify the sequence of changes involved in normal fertilization. It is unlikely that there was any permanent effect on the function of the cortical granules (see Szollosi, 1962, 1967) or on the block to polyspermy since only a very limited number of spermatozoa, usually two, entered the polyspermic eggs. On the other hand, the involvement of progesterone in development of the acrosome reaction has been suggested (Austin, Bavister \& Edwards, 1972), and the possibility of steroid involvement in the capacitation of porcine spermatozoa has been discussed (Hunter, 1972). If progesterone does act at the membrane level to facilitate the acrosome reaction, then this might indicate another mechanism whereby the local injections of progesterone led to an increased incidence of 
polyspermy. However, since polyspermic eggs were also found in control animals not injected with progesterone, the argument for an alteration in tubal environment - in this case, possibly due to trauma associated with insertion of the needle-is strengthened at the expense of the case for a direct effect of progesterone on the gametes.

A consistent finding in this study was the disposition of the nuclear elements in the dispermic pronuclear eggs. The female and a single male pronucleus undergoing syngamy occupied a peripheral position in one hemisphere of the egg adjacent to the polar bodies, whereas the accessory male pronucleus was invariably located subcentrally or peripherally in the opposite hemisphere of the egg. Such a failure of pronuclear migration in pigs was also noted by Baker \& Coggins (1968) and Hunter \& Léglise (1971), and may suggest the existence of a mechanism that operates to inhibit or reduce the chances of syngamy commencing between more than a single male and the female pronucleus. In the case of the digynic egg reported above, union of three pronuclei had clearly occurred. But whether organelles associated with the accessory spermatozoa are involved in the apparent interference with the central migration of pronuclei must await the results of ultrastructural studies. Although the failure of conjugation of more than one male pronucleus with the female was a characteristic of both dispermic and trispermic eggs in this study, a subsequent incorporation of accessory male elements into the arrangement of condensing chromatin cannot be ruled out.

The observed synchrony of pronuclear development, as judged by similarity in the appearance of the two male pronuclei, suggests that the polyspermic condition arose as a sequel to simultaneous or almost simultaneous penetration of the ooplasm by spermatozoa traversing the zona pellucida on opposing sides of the egg. The location of the male pronuclei in the dispermic and trispermic eggs would also support this proposition. Only in one polyspermic egg were there both mature pronuclei and recently penetrated sperm heads, indicating entry of a second spermatozoon into the ooplasm some considerable time after the initial penetration. Under circumstances in which the block to polyspermy or zona reaction (Braden, Austin \& David, 1954) is propagated from the point of entry of the first spermatozoon into the ooplasm, the chances of the polyspermic condition arising would clearly be greatest if accessory spermatozoa penetrated opposite hemispheres of the egg at approximately the same time before completion of the zona reaction (see Hunter \& Dziuk, 1968). Arguments along these lines have been developed to account for the occurrence of polyspermy in other mammalian species (Braden, Austin \& David, 1954; Austin \& Walton, 1960). A question that arises from the present experiments is whether treatment with progesterone may have impaired the efficiency of the block to polyspermy due to some effect on the rate of liberation of the contents of the cortical granules or on the nature of the zona pellucida. However, if this were the case, it would be difficult to explain why polyspermy arose only in a proportion of the eggs, unless the eggs released during any one period of oestrus in the pig vary in their susceptibility to polyspermy.

The proportion of polyspermic eggs in which syngamy between the female and more than one male pronucleus would occur remains uncertain, as does the 
ability of polyspermic pig eggs to form a normal mitotic spindle. The results of other studies in this laboratory (unpublished) suggest that cleavage is retarded in polyspermic eggs when compared with eggs fertilized normally in the same animal, and that fragmentation of pronuclear eggs into two cells rather than cleavage organized about a mitotic spindle may occur in a proportion of these eggs. On the other hand, Bomsel-Helmreich (1961) has examined the fate of triploid pig embryos arising under conditions of delayed mating, but the proportion of triploids that originated from dispermic fertilization, as distinct from digyny, was unknown. In the light of the present observations on polyspermic fertilization, it seems possible that Bomsel-Helmreich (1961) may have overestimated the proportion of triploid pig embryos arising from delayed mating and, by the same token, the nature of the subsequent embryonic mortality.

Finally, it should be noted that the spermatozoa of only one boar were used throughout these experiments. Although this male was known to be of high fertility, aspects of the genotype expressed on the sperm head may either have facilitated penetration of the' egg membranes or may have been less likely to evoke a rapid block to polyspermy when compared with spermatozoa of different genetic constitution. Evidence from other experiments at this Unit indicates that the incidence of polyspermy in pigs may be influenced by the genotype of the male (C. Polge and R. D. Baker, unpublished). Braden (1958) noted that the proportion of mouse eggs in which more than one spermatozoon traversed the zona pellucida varied significantly according to the strain of the male employed in any one mating. In the same context, Beatty (1970) has raised the possibility that penetration of the egg membranes depends on the genetic status of the spermatozoon, whilst penetration into the vitellus depends on the genetic status of the egg.

\section{ACKNOWLEDGMENTS}

This study was undertaken during tenure of a Senior Research Fellowship from the Milk Marketing Board, for which grateful acknowledgment is made.

I would like to thank Professor T. Mann for the hospitality of his Unit, Dr C. Polge for the provision of facilities in his laboratory and for much helpful advice, and the staff of the Animal Research Station for their invaluable assistance. Text-figure 1 was drawn by Monsieur P. C. Léglise, and a number of other colleagues kindly read and commented on the manuscript.

\section{REFERENCES}

ANDERSEN, D. H. (1928) Comparative anatomy of the tubo-uterine junction. Histology and physiology in the sow. Am. F. Anat. 42, 255.

Austin, C. R. (1961) The mammalian egg. Blackwell Scientific Publications, Oxford.

Austin, G. R., Bavister, B. D. \& Edwards, R. G. (1972) Components of capacitation. In: The Regulation of Mammalian Reproduction. NIH Bethesda Conference. (In press).

Austin, C. R. \& Bishop, M. W. H. (1957) Fertilization in mammals. Biol. Rev. 32, 296.

Austin, C. R. \& Walton, A. (1960) Fertilization. In: Marshall's Physiology of Reproduction, Vol. 1, Part 2, Chapter 10. Ed. A. S. Parkes. Longmans Green, London.

BAKER, R. D. \& Coggrns, E. G. (1968) Control of ovulation rate and fertilization in prepuberal gilts. J. Anim. Sci. 27, 1607. 
Beatty, R. A. (1970) The genetics of the mammalian gamete. Biol. Rev. 45, 73.

Bomsel-Helmreich, O. (1961) Hétéroploïdie expérimentale chez la truie. Proc. IVth Int. Congr. Anim. Reprod., The Hague, 3, 578.

BrADEN, A. W. H. (1958) Variation between strains of mice in phenomena associated with sperm penetration and fertilization. 7. Genet. 56, 1.

Braden, A. W. H., Austin, C. R. \& David, H. A. (1954) The reaction of the zona pellucida to sperm penetration. Aust. F. biol. Sci. 7, 391 .

Chang, M. C. (1952) Fertilizability of rabbit ova and the effects of temperature in vitro on their subsequent fertilization and activation in vivo. 7. exp. Zool. 121, 351.

Day, B. N. \& Polge, G. (1968) Effects of progesterone on fertilization and egg transport in the pig. $\mathcal{F}$. Reprod. Fert. 17, 227.

Du Mesnil du Buisson, F. \& Dauzier, L. (1955) Distribution et résorption du sperme dans le tractus génital de la truie: survie des spermatozoïdes. Annls Endocr. 16, 413.

Hancock, J. L. (1959) Polyspermy of pig ova. Anim. Prod. 1, 103.

Hunter, R. H. F. (1967a) The effects of delayed insemination on fertilization and early cleavage in the pig. 7. Reprod. Fert. 13, 133.

Hunter, R. H. F. (1967b) Polyspermic fertilization in pigs during the luteal phase of the estrous cycle. J. exp. Zool. 165, 451 .

Hunter, R. H. F. (1967c) Porcine ovulation after injection of human chorionic gonadotrophin. Vet. Rec. 81, 21.

Hunter, R. H. F. (1972) Fertilization in the pig: sequence of nuclear and cytoplasmic events. $\mathcal{F}$. Reprod. Fert. 29, 395.

Hunter, R. H. F. \& Dziuk, P. J. (1968) Sperm penetration of pig eggs in relation to the timing of ovulation and insemination. J. Reprod. Fert. 15, 199.

Hunter, R. H. F. \& LÉglise, P. C. (1971) Polyspermic fertilization following tubal surgery in pigs, with particular reference to the rôle of the isthmus. J. Reprod. Fert. 24, 233.

Melrose, D. R. \& O'Hagan, C. (1961) Investigations into the techniques of insemination in the pig. Proc. IVth Int. Congr. Anim. Reprod., The Hague, 4, 855.

Pıkó, L. (1961) La polyspermie chez les animaux. Annls Biol. anim. Biochim. Biophys. 1, 323.

Pitxjanen, I. G. (1955) Ovulation, fertilization and the early stages of embryonic development in pigs. Izv. Akad. Nauk. S.S.S.R., Ser. Biol. 3, 120.

RigBy, J. P. (1966) The persistence of spermatozoa at the uterotubal junction of the sow. $\mathcal{7}$. Reprod. Fert. 11, 153.

Szollosi, D. (1962) Cortical granules: a general feature of mammalian eggs? 7. Reprod. Fert. 4, 223.

Szollosi, D. (1967) Development of cortical granules and the cortical reaction in rat and hamster eggs. Anat. Rec. 159, 431.

Thrbault, G. (1959) Analyse de la fécondation de l'œuf de la truie après accouplement ou insémination artificielle. Annls Zootech. Sér. D, Suppl. 8, 165. 